Relations industrielles

Industrial Relations

\title{
In memoriam: Émile Bouvier, S.J. 1906-1985
}

\section{Gérard Hébert}

Volume 40, numéro 2, 1985

URI : https://id.erudit.org/iderudit/050129ar

DOI : https://doi.org/10.7202/050129ar

Aller au sommaire du numéro

Éditeur(s)

Département des relations industrielles de l'Université Laval

ISSN

0034-379X (imprimé)

1703-8138 (numérique)

Découvrir la revue

Citer ce document

Hébert, G. (1985). In memoriam: Émile Bouvier, S.J. 1906-1985. Relations

industrielles / Industrial Relations, 40(2), 211-212.

https://doi.org/10.7202/050129ar

Tous droits réservés @ Département des relations industrielles de l'Université Laval, 1985
Ce document est protégé par la loi sur le droit d'auteur. L’utilisation des services d'Érudit (y compris la reproduction) est assujettie à sa politique d'utilisation que vous pouvez consulter en ligne.

https://apropos.erudit.org/fr/usagers/politique-dutilisation/ 


\section{In memoriam}

\section{EMILE BOUVIER, S.J. 1906-1985}

Dans la nuit du 16 au 17 mars, au Centre hospitalier de Sherbrooke, décédait le Père Emile Bouvier, jésuite. Il aurait eu 79 ans douze jours plus tard.

Né à Montréal le 29 mars 1906, il fit ses études classiques au Collège Sainte-Marie (1917-1923). Entré chez les jésuites à l'âge de 17 ans, le 7 septembre 1923, il fut ordonné prêtre le 15 août 1937. Il avait obtenu son doctorat en sciences économiques à l'Université Georgetown, à Washington, en 1932. Une fois sa formation de jésuite terminée, il fit deux années d'études post-doctorales à l'Université Harvard avec, entre autres, Joseph Schumpeter et Sumner Slichter. Il revint enseigner l'économie politique et les relations industrielles à Montréal à compter de 1941. Il enseigna d'abord à l'École de service social logée dans l'École des hautes études commerciales rue Viger.

Dès ses premières années d'enseignement, le Père Émile Bouvier prépare la fondation d'une école universitaire de relations industrielles. Ses travaux se concrétisent quelques années plus tard: le 5 février 1945, Édouard Montpetit prononçait la leçon inaugurale, dans le nouvel édifice de la montagne, de la Section des relations industrielles de l'Université de Montréal. La Section donnait les premiers cours de jour dans la Faculté des sciences sociales, économiques et politiques, qui n'avait été jusque là qu'une faculté de soir, menant à un certificat. La nouvelle Section décernait à ses étudiants la Maîtrise en relations industrielles'.

Tous ceux qui ont connu le Père Bouvier, tant ses amis que ses ennemis - et il en eut de très fidèles dans les deux camps - lui reconnaissaient des talents de défricheur. Sans son audace, sa ténacité, son dynamisme et sa formation antérieure en économie politique, personne n'aurait pu réussir cet exploit que d'établir un nouveau département, entièrement consacré aux relations industrielles, alors que l'Université de Montréal connaissait des difficultés financières énormes. À la Section, le Père Bouvier a jeté les bases non seulement de l'enseignement mais également de la recherche, des bibliothèques et du rayonnement. Les premiers congrès, les premières publications de l'École datent des années où il fut directeur et professeur, soit de 1945 à 1951 .

En 1949, il avait participé à la réorganisation de l'Institut d'administration de l'Université de Tientsin en Chine. En 1952, il fonde une autre école de relations industrielles, cette fois à l'Université Ibero Americana de Mexico, où il enseignait déjà occasionnellement depuis quelques années. De 1954 à 1959, il est directeur du Département d'économie politique à l'Université Georgetown. En 1959, il devient recteur de l'Université de Sudbury et il sera, en 1960, le premier recteur de la toute nouvelle Université Laurentienne de Sudbury.

1 Dans l'ouvrage collectif, Les sciences sociales au Québec, continuité ou rupture, Montréal, Presses de l'Université de Montréal, 1984, ch. VIII, pp. 131-146, “Les transformations des sciences sociales à l'Université de Montréal», le R.P. Émile Bouvier a exposé lui-même le rôle qu'il a joué de même que les principes qui ont orienté son action.

Relat. ind., vol. 40, no 2, 1985 (C) PUL ISSN 0034-379 X 
En 1963, il revient au Québec, comme premier directeur du Département d'économique et professeur de relations industrielles à l'Université de Sherbrooke. Après avoir parcouru le monde pendant les vingt premières années de sa carrière, il passa les vingt dernières à l'Université et dans la région de Sherbrooke. En 1979 il est nommé professeur émérite, mais il continue d'enseigner malgré qu'il ait déjà dépassé l'âge de la retraite. Il donnait encore neuf heures de cours par semaine, et c'est pendant l'un de ces cours, le 15 mars 1985, qu'il ressentit le malaise qui devait l'emporter la nuit d'après.

Toute la vie du Père Bouvier a été consacrée à l'enseignement et à l'administration universitaire, ainsi qu'à la recherche et aux publications dans le domaine qui l'a toujours préoccupé, celui de l'économie politique et des relations industrielles. Comme tous les bâtisseurs, ses écrits reflètent les préoccupations de l'époque où ils paraissent. Surtout dans les premières années, ils avaient une orientation pratique et politique, certains diront un caractère polémique. Au moment de sa mort, il avait deux livres sur le métier, toujours en économique et en relations industrielles, et il se préoccupait du sort que l'on ferait à l'importante documentation qu'il avait accumulée tout au cours de sa longue carrière de professeur et d'homme d'action.

Car le Père Bouvier fut également un entraîneur. D'autres avant lui avaient tenté de mettre sur pied une association patronale au Québec. Leurs efforts avaient toujours tourné court. Le Père Bouvier établit, dès le début des années 1940, l'Association professionnelle des industriels, sur une base stable et définitive. L'A.P.I. devait devenir le Centre des dirigeants d'entreprises, une vingtaine d'années plus tard, au moment où l'Association elle-même donnait naissance au Conseil du patronat du Québec. Dans la région de Sherbrooke, où il était profondément intégré, il occupa plusieurs postes d'influence, comme celui de Président de la Chambre de commerce, de Vice-président du Conseil régional de développement, et plusieurs autres. Il a également présidé et mené à bien plusieurs études sur divers problèmes et divers secteurs de l'économie et des relations du travail.

Le Père Bouvier a également reçu plusieurs distinctions au cours de sa carrière, comme la plaque de l'Association des conseillers en relations industrieiles et, récemment, le titre de membre d'honneur de la Corporation, le prix du sénateur Bélisle, à Sudbury, l'éméritat à l'Université de Sherbrooke, le prix du Conseil du patronat du Québec. Un mois avant sa mort, le 7 février 1985, le recteur Paul Lacoste de l'Université de Montréal lui décernait la médaille de l'Université pour avoir fondé, 40 ans plus tôt, l'École de relations industrielles de l'Université de Montréal.

C'est à ce titre, tout particulièrement, compte tenu du dynamisme, de la probité intellectuelle et de la conscience professionnelle qu'il a su transmettre aux premiers étudiants de cette École, et par eux à tous leurs successeurs, que la communauté des relations industrielles de Montréal et de tout le Québec lui est particulièrement redevable et lui rend l'hommage dû aux bâtisseurs. L'honneur qu'il a reçu du recteur de l'Université de Montréal, si peu de temps avant sa mort, fermait, en quelque sorte, la brèche de sa longue absence de cette institution. Son départ si rapide après cette reconnaissance, qu'il n'avait ni cherchée ni souhaitée, a des airs d'un Nunc dimittis.

7 avril 1985 . 